\title{
Causes of differences in model and satellite tropospheric warming rates
}

Article

Accepted Version

Santer, B. D., Fyfe, J. C., Pallotta, G., Flato, G. M., Meehl, G. A., England, M. H., Hawkins, E., Mann, M. E., Painter, J. F., Bonfils, C., Cvijanovic, I., Mears, C., Wentz, F. J., Po-Chedley, S., Fu, Q. and Zou, C.-Z. (2017) Causes of differences in model and satellite tropospheric warming rates. Nature Geoscience, 10 (7). pp. 478-485. ISSN 1752-0894 doi: https://doi.org/10.1038/ngeo2973 Available at https://centaur.reading.ac.uk/71264/

It is advisable to refer to the publisher's version if you intend to cite from the work. See Guidance on citing.

To link to this article DOI: http://dx.doi.org/10.1038/ngeo2973

Publisher: Nature Publishing Group

All outputs in CentAUR are protected by Intellectual Property Rights law, including copyright law. Copyright and IPR is retained by the creators or other copyright holders. Terms and conditions for use of this material are defined in the End User Agreement. 


\section{CentAUR}

Central Archive at the University of Reading

Reading's research outputs online 
1

2

3

4

5

6

$7{ }^{1}$ Program for Climate Model Diagnosis and Intercomparison (PCMDI), Lawrence

8 Livermore National Laboratory, Livermore, CA 94550, USA.

$9{ }^{2}$ Canadian Centre for Climate Modelling and Analysis, Environment and Climate

10 Change Canada, Victoria, British Columbia, V8W 2Y2, Canada.

${ }_{11}^{3}$ National Center for Atmospheric Research, Boulder, Colorado 80307, USA.

${ }_{12}{ }^{4}$ ARC Centre of Excellence for Climate System Science, University of New South 13 Wales, New South Wales 2052, Australia.

${ }_{14}{ }^{5}$ National Centre for Atmospheric Science, Department of Meteorology, University of 15 Reading, Reading RG6 6BB, UK.

${ }_{16}{ }^{6}$ Department of Meteorology and Earth and Environmental Systems Institute, Penn17 sylvania State University, University Park, Pennsylvania, USA. 
18

19

20

21 20740, USA.

${ }^{7}$ Remote Sensing Systems, Santa Rosa, CA 95401, USA.

${ }^{8}$ Dept. of Atmospheric Sciences, University of Washington, Seattle, WA 98195, USA.

${ }^{9}$ Center for Satellite Applications and Research, NOAA/NESDIS, College Park, MD

Revised: May 25, 2017 
24

In the early 21st century, satellite tropospheric warming trends were generally smaller than trends estimated from a large multi-model ensemble. Because observations and coupled model simulations do not have the same phasing of natural internal variability, such decadal differences in simulated and observed warming rates invariably occur. Here we analyse global-mean tropospheric temperatures from satellites and climate model simulations to determine whether warming rate differences over the satellite era can be explained by internal climate variability alone. We find that in the last two decades of the 20th century, differences between modeled and observed tropospheric temperature trends are broadly consistent with internal variability. Over most of the early 21st century, however, model tropospheric warming is substantially larger than observed; warming rate differences are generally outside the range of trends arising from internal variability. There is a low probability (between zero and $\approx 9 \%$ ) that multi-decadal internal variability fully explains the asymmetry between the late 20 th and early 21 st century results. It is also unlikely that this asymmetry is due to the combined effects of internal variability and a model error in climate sensitivity. We conclude that model overestimation of tropospheric warming in the early 21 st century is partly due to systematic deficiencies in some of the post-2000 external forcings used in the model simulations. 
45 The Fifth Assessment Report of the Intergovernmental Panel on Climate Change

46 (IPCC) contained prominent discussion of differences between warming rates in ob47 servations and model simulations [1, 2]. The focus of the discussion was on two issues:

48 the causes of a putative "slowdown" in observed surface and tropospheric warming

49

50

51

during the early 21st century, and the reasons for the inability of most climate model simulations to capture this behavior. The IPCC defined the "slowdown" as a substantially reduced surface warming trend over 1998 to 2012 relative to the long-term warming over 1951 to 2012 [2].

Since publication of the Fifth Assessment Report, at least three different interpretations of the "slowdown" have emerged. One interpretation is that this phenomenon is largely an artifact of residual errors in surface temperature data sets [3, 4, 5]. A second school of thought holds that the "slowdown" is primarily a routine decadal fluctuation in temperature [6], and is not statistically distinguishable from previous manifestations of internal variability $[7,8,9]$. A third interpretation is that the "slowdown" is attributable to the combined effects of different modes of internal variability [10, 11, 12, 13, 14] and multiple external forcings [15, 16, 17].

It is of interest to examine some implications of these schools of thought. If the reduction in early 21st century warming is mainly an artifact of errors in surface temperature data [3, 5], independent, satellite-based measurements of tropospheric temperature should show little evidence of a recent "slowdown" in warming - consistent 
65

66

67

68

with corrected surface results. Current satellite datasets, however, provide support for a reduced rate of tropospheric warming in the early 21st century [15, 16, 18].

If the "slowdown" is predominantly a routine manifestation of internal variability (and if model-based estimates of the forced temperature signal and internal variability are realistic), then the differences between simulated and observed warming rates arise solely from different phasing of internal variability in "model world" and in the real world. Under this interpretation, model-versus-observed warming rate differences should be fully consistent with internal variability.

In the third school of thought, both internal variability and external forcing contribute to the "slowdown" 2, 19]. The externally forced contribution is due to the combined cooling effects of a succession of moderate early 21st century eruptions [15, 20, 21, 22, 23, 24], a long and anomalously low solar minimum during the last solar cycle [25], increased atmospheric burdens of anthropogenic sulfate aerosols [17, 26], and a decrease in stratospheric water vapor [27]. There are known systematic errors in these forcings in model simulations performed in support of the IPCC Fifth Assessment Report [2, 17, 19, 20, 27]. These errors arise in part because the simulations were performed before more reliable estimates of early 21st century forcing became available [20, 27]. The net effect of the forcing errors is that the simulations underestimate some of the cooling influences contributing to the observed "slowdown".

We find that for tropospheric temperature, model-versus-observed warming rate 
85

differences during most of the early 21 st century cannot be fully explained by natural internal variability of the climate system. We consider whether this result provides support for the third school of thought, or if it could be plausibly explained by the combined effects of a model error in climate sensitivity [28] and different phasing of modeled and observed internal variability [10, 11, 12, 13, 14].

Our focus is on satellite- and model-based estimates of tropospheric temperature. There are two reasons for this choice. First, satellite tropospheric temperature measurements have time-invariant, near-global coverage [29, 30, 31]. In contrast, there are large, non-random temporal changes in spatial coverage in the observed surface temperature datasets used in most "slowdown" studies [3, 19, 32]. Second, satellite tropospheric temperature datasets have been a key component of recent claims that current climate models are too sensitive (by a factor of three or more) to humancaused changes in greenhouse gases [28, 33]. Errors of this magnitude would diminish confidence in model projections of future climate change. It is therefore critically important to evaluate the validity of such claims.

\section{Satellite and model temperature data}

Our analysis primarily relies on satellite-based measurements of global-scale changes in the temperature of the mid- to upper troposphere (TMT). TMT data with nearglobal coverage are available from three groups: Remote Sensing Systems (RSS) [29], 
the Center for Satellite Applications and Research (STAR) [31, and the University of Alabama at Huntsville (UAH) [34]. Older and more recent dataset versions are provided by each of these groups (see Methods). A fourth group (the University of Washington; UW) [30] produces TMT data for a tropical domain. We briefly discuss both tropical TMT changes and global-scale changes in the temperature of the lower troposphere (TLT); the latter are provided by RSS and UAH only.

Model TMT data are from simulations of historical climate change (HIST) and of 21st century climate change under Representative Concentration Pathway 8.5 (RCP8.5). These simulations yield information on the tropospheric temperature response to combined anthropogenic and natural external forcing. To compare models and observations over the full satellite temperature record (January 1979 to December 2016), HIST and RCP8.5 temperatures were spliced together ("HIST+8.5"). We also analyze control runs with no changes in external forcings. Control runs are one of a number of different sources of information on natural internal climate variability [35, 36, 37, 38. The HIST, RCP8.5, and control simulations were performed under phase 5 of the Coupled Model Intercomparison Project (CMIP5) [39].

Because TMT receives a contribution from the cooling of the stratosphere, a standard regression-based approach was employed to correct for this influence [40]. Correction yields a more representative measure of bulk changes in tropospheric temperature [41, 42, 43], and was performed for both satellite and model TMT data. 
Further information on the correction method and the satellite and model temperature data is provided in the Methods section and the Supplementary Information.

\section{Tropospheric temperature time series}

The multi-model average (MMA) of TMT changes in the HIST+8.5 simulations is smoother than any individual observational TMT time series (see Fig. 1A). This difference in the amplitude of variability is expected [12, 15, 44]. In "free running" simulations with coupled models of the climate system, the phasing of internally generated climate variability is random. By averaging over 49 realizations of HIST+8.5 (performed with 37 different climate models), the amplitude of random variability is reduced, more clearly revealing the underlying temperature response to external forcings. The real world, however, has only one sequence of internal climate variability.

Tropospheric warming is larger in the MMA than in the satellite data [45] (Figs. 1A, B). Another prominent feature of the observed results is the large interannual temperature variability arising from the internally generated El Niño/Southern Oscillation (ENSO). The positive (El Niño) phase of ENSO causes short-term warming. The large 1982/83 El Niño partly obscured cooling caused by the 1982 eruption of El Chichón. Because of the above-described noise reduction arising from averaging over realizations and models, the cooling signatures of El Chichón and Pinatubo are clearer in the MMA [15, 46]. Removal of temperature variability induced by ENSO 
improves the agreement between volcanic cooling signals in the MMA and in satellite tropospheric temperature data, but does not fully explain mismatches between simulated and observed tropospheric warming during the early 21st century [15].

\section{Significance of individual difference series trends}

Next, we assess whether there are statistically significant differences between tropospheric temperature changes in models and individual satellite temperature datasets. We operate on the difference series $\Delta T_{f-o}(k, t)=\overline{\bar{T}}_{f}(t)-T_{o}(k, t)$, where $k$ is an index over the number of satellite datasets, $t$ is an index over time (in months), $\overline{\bar{T}}_{f}(t)$ is the MMA, and $T_{o}(k, t)$ is an individual observational temperature time series. The subscripts $f$ and $o$ denote results from forced simulations and observations (see Methods and statistical terminology section in the Supplementary Information).

Our significance testing procedure rests on two assumptions. First, we assume that the MMA provides a credible, "noise free" estimate of the true (but unknown) externally forced tropospheric temperature signal in the real world. If this assumption is valid, the difference series $\Delta T_{f-o}(k, t)$ should reflect the departures of the observed realization of internal variability from the externally forced signal. A second necessary assumption is that the CMIP5 control runs provide unbiased estimates of the amplitude, period, and frequency of major modes of natural internal variability, particularly on interannual to multi-decadal timescales. Whether this assumption is 
162

justifiable is discussed in the final section of the paper.

Under these two assumptions, we formulate the null hypothesis that departures between the expected and observed tropospheric temperature trends are consistent with internal climate noise. Rejection of the null hypothesis can have multiple explanations: systematic deficiencies in the external forcings applied in the HIST+8.5 simulations (such as neglect of moderate volcanic eruptions in the early 21st century [20, 21, 22, 23]), errors in the climate sensitivity to external forcings, errors in the simulated spectrum of internal variability, and residual inhomogeneities in the satellite temperature measurements. These explanations are not mutually exclusive.

Most previous studies of differences between simulated and observed warming rates in the early 21 st century focused on changes over specific periods [3, 16, 47, 48]. The appropriateness of different analysis period choices has been the subject of debate [3, 16, 19]. To avoid such debate, we focus instead on $L$-year analysis timescales. We consider five timescales here: $L=10,12,14,16$, and 18 years. For each timescale, an $L$-year "window" is advanced by one month at a time through $\Delta T_{f-o}(k, t)$. A least-squares linear trend is calculated for each individual window.

These maximally overlapping trends are plotted in the left column of Fig. 2. As expected, shorter $L$-year trends are noisier. For example, 10-year windows ending close to the peak tropospheric warming caused by the 1997/98 El Niño have large negative trends in the difference series. The use of longer trend-fitting periods damps 
such end-point effects. Another noteworthy feature of Fig. 2 is that most $L$-year windows which sample a substantial portion of the early 21st century have large positive trends in $\Delta T_{f-o}(k, t)$. During this period, the average simulated warming is larger than the tropospheric warming in each satellite dataset. We use CMIP5 control runs to estimate the probability that trends in $\Delta T_{f-o}(k, t)$ are either unusually large or unusually small relative to unforced temperature trends (see Methods). The resulting empirical $p$-values are plotted in the right-hand column of Fig. 2.

For most $L$-year trends ending after 2005, model-versus-observed differences in tropospheric warming are significantly larger (at the $10 \%$ level or better) than can be explained by natural internal variability alone. This result holds for all six satellite TMT datasets examined here. In contrast, $L$-year difference series trends ending before 2005 are generally not significantly larger than unforced TMT trends in the CMIP5 control runs. Qualitatively similar results are obtained for TMT averaged over the tropics, as well as for near-global changes in TLT (see Supplementary Figs. S1 and S2, respectively).

In each panel in the right-hand column of Fig. 2, there are upper and lower rejection regions for our stipulated null hypothesis. The upper (lower) rejection regions are for significant negative (positive) trends in $\Delta T_{f-o}(k, t)$. Under the null hypothesis, significant negative and positive trends in $\Delta T_{f-o}(k, t)$ should be equally likely. We find, however, that significant positive trends dominate. There is only one small 
group of significant negative trends in $\Delta T_{f-o}(k, t)$ - the group with end points close to the anomalous warmth of the 1997/98 El Niño.

Other features of Fig. 2 are also of interest. Consider, for example, the group of positive 10-year trends ending between approximately 1990 and 1993 (Fig. 2B). As noted above, El Chichón's cooling signal is larger and clearer in the MMA than in satellite TMT data, where it was partly masked by the 1982/83 El Niño. This explains why simulated TMT trends commencing close to the Chichón eruption tend to show a larger post-eruption recovery (and larger warming) than in the observations (Figs. $1 \mathrm{~A}$ and B). The influence of the $1982 / 83 \mathrm{El} \mathrm{Niño} \mathrm{on} \mathrm{trends} \mathrm{in} \Delta T_{f-o}(k, t)$ diminishes as the trend fitting period is increased.

The large tropospheric warming caused by the 2015/16 El Niño event also has a pronounced effect. As shorter (10- to 12-year) sliding windows sample this observed warming spike, the size of trends in the $\Delta T_{f-o}(k, t)$ difference series decreases, and $p$ values increase (Figs. 2B, D). However, as the longer 16- and 18-year sliding windows approach the end of the TMT records, even the anomalous observed warmth of late 2015 and early 2016 does not negate the larger simulated warming during most of the "slowdown" period - i.e., trends in $\Delta T_{f-o}(k, t)$ remain significantly larger than unforced trends (Figs. 2H, J).

Figure 2 reveals large structural uncertainties in satellite TMT datasets. These uncertainties reflect different choices in dataset construction, primarily related to the 
treatment of orbital drift, the impact of orbital drift on sampling the diurnal cycle of atmospheric temperature [29, 30, 31, 34, 49], and the influence of instrument body temperature [50, 51]. For example, versions 5.6 and 6.0 of the UAH TMT dataset have pronounced differences in tropospheric warming in the first third of the satellite record. These differences (which are probably due to an update in how the UAH group deals with instrument bias correction) are large enough to lead to different decisions regarding the statistical significance of initial trends in $\Delta T_{f-o}(k, t)$.

Our use of older and newer versions of satellite TMT records highlights the evolutionary nature of these datasets. This evolutionary understanding is not always well understood outside of the scientific community [33], which is why we choose to illustrate it in Fig. 2. In the following analysis, however, we focus on newer dataset versions, which incorporate adjustments for recently identified inhomogeneities, and are likely to be improved relative to earlier dataset versions [29, 30].

\section{Significance of asymmetry statistics}

The analysis in Fig. 2 focuses on the significance of individual trends in $\Delta T_{f-o}(k, t)$. It does not consider whether overall asymmetries in $p$-values (such as the preponderance of significant positive trends in the difference series) could be due to internal variability alone. To address this question, we define three asymmetry statistics. The first is $\gamma_{1}$, which measures asymmetry in the numbers of significant positive and significant 
negative trends in $\Delta T_{f-o}(k, t)$. The second and third are the $\gamma_{2}$ and $\gamma_{3}$ statistics, which provide information on asymmetries in the temporal distribution of individual $p$-values. To calculate $\gamma_{2}$ and $\gamma_{3}$, we split the number of maximally overlapping difference series trends into a first and second set of approximately equal size (SET 1 and SET 2; see Fig. 2). This is done for each value of the trend length $L$. The difference in the total number of significant positive trends in SET 1 and SET 2 is $\gamma_{2}$. The difference in "set-average" $p$-values is $\gamma_{3}$ (see Methods).

Figure 3 shows asymmetry statistics for the specific case of maximally overlapping 10-year trends in $\Delta T_{f-o}(k, t)$. The actual values of $\gamma_{1}, \gamma_{2}$ and $\gamma_{3}$ reveal a preponderance of significant positive trends in $\Delta T_{f-o}(k, t)$, a larger number of significant positive trends in SET 2 than in SET 1, and a sharp decrease in average $p$-values between SET 1 and SET 2 (see Figs. 3A, C, and E, respectively). We seek to estimate the likelihood that these actual values could be due to multi-decadal internal variability alone. We refer to these probabilities subsequently as $p_{\gamma_{1}}, p_{\gamma_{2}}$ and $p_{\gamma_{3}}$.

We begin by randomly selecting 5,000 surrogate "observed" TMT time series from the CMIP5 control runs (see Methods and Supplementary Figs. S3 and S4). For each surrogate time series, maximally overlapping $L$-year trends are compared with control run distributions of unforced $L$-year trends; $p$-values are calculated for each individual trend, and asymmetry statistics are computed from the $p$-values. This procedure yields 5,000-member null distributions of $\gamma_{1}, \gamma_{2}$ and $\gamma_{3}$. We know a priori 
that the statistical properties of these distributions are solely influenced by natural internal variability. Actual values of the asymmetry statistics are compared with the null distributions to estimate $p_{\gamma_{1}}, p_{\gamma_{2}}$ and $p_{\gamma_{3}}$ (see Figs. 3B, D, and F).

Figure 4 summarizes these probability estimates. By averaging over satellite datasets and analysis timescales, we obtain the overall probabilities $\overline{\overline{p_{\gamma_{1}}}}, \overline{\overline{p_{\gamma_{2}}}}$ and $\overline{\overline{p_{\gamma_{3}}}}$ (the magenta lines in Fig. 4). For the statistic gauging the asymmetry in the numbers of positive and negative difference series trends, $\overline{\overline{p_{\gamma_{1}}}} \approx 0.005$. On average, therefore, there is only a 1 in 200 chance that the actual preponderance of significant positive trends in $\Delta T_{f-o}(k, t)$ could be due to internal variability alone (Fig. $4 \mathrm{~A}$ ).

Consider next the temporal asymmetries between the properties of difference series trends in SET 1 and SET 2 (Figs. 4B and C). The likelihood is very small $\left(\overline{\overline{p_{\gamma_{2}}}} \approx\right.$ 0.004) that random internal fluctuations in climate could fully explain why the number of significant positive trends in $\Delta T_{f-o}(k, t)$ is larger in SET 2 than in SET 1. For the third asymmetry statistic, there is less than a 1 in 10 chance $\left(\overline{\overline{p_{\gamma_{3}}}} \approx 0.09\right)$ that the actual decline in average $p$-values between SET 1 and SET 2 is due to internal variability alone.

The probabilities in Fig. 4 are calculated separately for each asymmetry statistic. We also considered the joint behavior of $\gamma_{1}, \gamma_{2}$ and $\gamma_{3}$. We estimated $p_{\gamma_{123}}$, the likelihood that internal variability alone can simultaneously produce values of $\gamma_{1}, \gamma_{2}$ and $\gamma_{3}$ that are more extreme than their "satellite average" actual values (the brown 
vertical lines in Figs. 3B, D and F). The calculation of $p_{\gamma_{123}}$ was performed with the same Monte Carlo-generated sampling distributions employed for computing the individual probabilities $p_{\gamma_{1}}, p_{\gamma_{2}}$ and $p_{\gamma_{3}}$.

For each of the five analysis timescales, $p_{\gamma_{123}}$ is zero. This indicates that in the 5,000 realizations of surrogate observations, there is not a single realization in which multi-decadal internal variability can simultaneously explain the actual asymmetries in the sign and temporal distribution of significant trends in $\Delta T_{f-o}(k, t)$. We caution, however, that our estimate of $p_{\gamma_{123}}$ relies on non-independent information, and is therefore likely to be biased: $\gamma_{1}, \gamma_{2}$, and $\gamma_{3}$ are all calculated from the same set of $p$-values for maximally overlapping trends in $\Delta T_{f-o}(k, t)$. Nevertheless, our findings suggest that there is real value in considering the joint behavior of $\gamma_{1}, \gamma_{2}$ and $\gamma_{3}$, and that each statistic provides some unique information about the asymmetric distribution of difference series trends.

\section{"Perfect model" analysis}

It has been posited that the differences between modeled and observed tropospheric warming rates are solely attributable to a fundamental error in model sensitivity to anthropogenic greenhouse gas increases [28]. Several aspects of our results cast doubt on the "sensitivity error" explanation. First, it is difficult to understand why significant differences between modeled and observed warming rates should be preferentially 
concentrated in the early 21st century (see Fig. 2). A fundamental model sensitivity error should be manifest more uniformly in time. Second, a large sensitivity error should appear not only in trend behavior, but also in the response to major volcanic eruptions [46]. After removal of ENSO variability, however, there are no large systematic model errors in tropospheric cooling following the eruptions of El Chichón in 1982 and Pinatubo in 1991 [15].

We performed a "perfect model" analysis to further investigate this issue. We consider whether asymmetries in the sign and temporal distribution of significant trends in $\Delta T_{f-o}(k, t)$ could be solely due to the combined effects of a large model sensitivity error and different realizations of modeled and observed internal variability. The "perfect model" study emulates our analysis of the "MMA minus satellite" difference series. Now, however, the difference series $\Delta T_{f-f}(j, t)$ is formed between the MMA and each individual HIST+8.5 realization. We calculate "perfect model" values of the $\gamma_{1}, \gamma_{2}$ and $\gamma_{3}$ statistics not only over 1979 to 2016 , but also over three earlier and two later 38-year analysis periods (see Methods).

For each asymmetry statistic, our "perfect model" analysis yields 288 individual samples. This allows us to explore how $\gamma_{1}, \gamma_{2}$ and $\gamma_{3}$ behave over a large range of inter-model differences in climate sensitivity and phasing of low-frequency modes of variability (Supplementary Fig. S5). Because consistently derived estimates of Equilibrium Climate Sensitivity (ECS) are not available for all CMIP5 models, we 
use a simple ECS proxy to study relationships between climate sensitivity and the "perfect model" values of $\gamma_{1}, \gamma_{2}$ and $\gamma_{3}$. This proxy, $\Delta T_{8.5}$, is the global-mean change in corrected TMT over 2006 to 2095; $\Delta T_{8.5}$ can be calculated from all 37 models for which we have RCP8.5 simulations (see Supplementary Fig. S6).

Relationships between the "perfect model" results and $\Delta T_{8.5}$ are shown in Supplementary Fig. S7. Results are partitioned into two groups. The first group is for the three earlier analysis periods (1862 to 1899,1900 to 1937 , and 1940 to 1977). The second group contains results for three later analysis periods (1979 to 2016, 2020 to 2057 and 2058 to 2095). For both groups of results, there are only weak relationships between $\Delta T_{8.5}$ and the statistics capturing temporal asymmetries in trend behavior $\left(\gamma_{2}\right.$ and $\left.\gamma_{3}\right)$. In contrast, the statistic reflecting asymmetries in trend sign $\left(\gamma_{1}\right)$ is highly correlated with $\Delta T_{8.5}$, but only during the three later analysis periods.

The latter result has several explanations. First, inter-model differences in ECS become more pronounced as greenhouse gas forcing increases. These sensitivity differences are manifest as a time-increasing spread in tropospheric warming rates (Supplementary Fig. S5). As this spread grows in the 21st century, high-ECS (low ECS) models yield a larger number of significant negative (positive) trends in the $\Delta T_{f-f}(j, t)$ difference series, and $\gamma_{1}$ becomes more highly correlated with $\Delta T_{8.5}$. Second, as trends in $\Delta T_{f-f}(j, t)$ become larger, the correlation between $\Delta T_{8.5}$ and $\gamma_{1}$ is less affected by natural decadal variability (Supplementary Fig. S8). 
Despite the fact that our "perfect model" analysis encompasses a large range of inter-model climate sensitivity differences, the average actual values of the three asymmetry statistics (the brown vertical lines in Figs. 3B, D, and F) remain unusual. For $\gamma_{1}$, there are only 12 out of 288 cases where the "perfect model" result exceeds the actual value (Supplementary Fig. S9A). This yields a probability of $p_{\gamma_{1}}=0.042$ that the actual $\gamma_{1}$ value could be due to the combined effects of a model error in climate sensitivity and different phasing of modeled and observed internal variability. For the statistics gauging temporal asymmetry, this likelihood is even smaller: $p_{\gamma_{2}}=$ 0.010, and $p_{\gamma_{3}}=0.038$ (Supplementary Figs. S9B, C). Finally, if the behavior of the asymmetry statistics is examined jointly rather individually, there is only one out of 288 cases in which the "perfect model" values of $\gamma_{1}, \gamma_{2}$ and $\gamma_{3}$ are simultaneously more extreme than the average actual values, and $p_{\gamma_{123}}=0.003$.

In contrast, statistically unusual values of all three asymmetry statistics could have been plausibly generated by the temporal coincidence of multiple externally forced and internally generated cooling influences in the early 21st century. Internally driven contributions to the "warming slowdown" arise from the transition to a negative phase of the Interdecadal Pacific Oscillation (IPO) in roughly 1999 [11, 13, 16, 52], and from changes in the phasing of other internal variability modes [14, 53]. Our statistical results are best explained by the combined effects of these known phase changes and by previously identified systematic model forcing errors in the early 21st century [2, 17, 20, 25, 27]. 


\section{${ }_{361}$ Reliability of model variability estimates}

The credibility of our findings depends on the reliability of model-based estimates of natural variability. If CMIP5 models systematically underestimated the amplitude of tropospheric temperature variability on 10- to 18-year timescales, it would spuriously inflate the significance of individual difference series trends. In previous work, we found no evidence of such a systematic low bias. On average, CMIP5 models slightly overestimated the amplitude of decadal variability in TMT [54].

It is more difficult to assess the credibility of our estimated probabilities for the overall asymmetry statistics shown in Figs. 3 and 4 . Such an evaluation requires information on model performance in capturing the "real-world" variability of tropospheric temperature on longer 30- to 40-year timescales. This information is not directly available from relatively short satellite TMT records, and must instead be inferred from other sources (see Supplementary Information). Such indirect sources do not support a systematic model underestimate of tropospheric temperature variability on 30- to 40-year timescales [55]. Note also that a low bias in model estimates of longer-timescale variability is physically inconsistent [56] with the above-mentioned claim of a high bias in model climate sensitivity [28].

A related issue is the fidelity with which models capture the periods of multidecadal oscillations. Underestimates of these periods could bias the sampling distributions of the $\gamma_{2}$ and $\gamma_{3}$ statistics, in both the "perfect model" analysis and the 
381

analysis with surrogate observations. There is some evidence that such an error may exist for the IPO [57], although it is difficult to make a reliable assessment of this type of error given relatively short observational record lengths and the obfuscating effects of low-frequency changes in external forcings [26].

In conclusion, the temporary "slowdown" in warming in the early 21st century has provided the scientific community with a valuable opportunity to advance understanding of internal variability and external forcing, and to develop improved climate observations, forcing estimates, and model simulations. Further work is necessary to reliably quantify the relative magnitudes of the internally generated and externally forced components of temperature change. It is also of interest to explore whether surface temperature yields results consistent with those obtained here for tropospheric temperature.

Our analysis is unlikely to reconcile divergent schools of thought regarding the causes of differences between modeled and observed warming rates in the early 21st century. However, we have shown that each hypothesized cause may have a unique statistical signature. These signatures should be exploited in improving understanding. While scientific discussion about the causes of short-term differences between modeled and observed warming rates is likely to continue [19], this discussion does not cast doubt on the reality of long-term anthropogenic warming. 


\section{${ }_{400}$ Methods}

401

\section{Satellite temperature data}

We use satellite estimates of tropospheric temperature change produced by RSS [29, 58], STAR [31, 59, 60], UAH [34], and the University of Washington (UW) [30]. The UW group supplies TMT data for the tropics only. All other groups have near-global coverage of TMT measurements.

RSS, UAH, and STAR produce satellite measurements of the temperature of the lower stratosphere (TLS), which is used to correct TMT for the influence it receives from stratospheric cooling. Only RSS and UAH supply measurements of the temperature of the lower troposphere (TLT), which we briefly discuss in the main text.

UAH provides two different versions (5.6 and 6.0) of their TLS, TMT, and TLT datasets. RSS currently has only one version (3.3) of their TLS and TLT datasets, but two versions (3.3 and 4.0) of their TMT product. Two versions were available for the STAR TLS and TMT datasets (3.0 and 4.0). At present, there is only one version (1.0) of the UW tropical TMT dataset.

Satellite datasets are in the form of monthly means on $2.5^{\circ} \times 2.5^{\circ}$ latitude/longitude grids. Near-global averages of TMT and TLT were calculated over areas of common coverage in the RSS, UAH, and STAR datasets $\left(82.5^{\circ} \mathrm{N}\right.$ to $82.5^{\circ} \mathrm{S}$ for TMT, and 
$82.5^{\circ} \mathrm{N}$ to $70^{\circ} \mathrm{S}$ for TLT). All tropical averages are over $20^{\circ} \mathrm{N}$ to $20^{\circ} \mathrm{S}$. At the time this analysis was performed, satellite temperature data were available for the 456-month period from January 1979 to December 2016.

\section{Method used for correcting TMT data}

Trends in TMT estimated from microwave sounders receive a substantial contribution from the cooling of the lower stratosphere [40, 41, 61, 62]. In ref. [40, a regressionbased method was developed for removing the bulk of this stratospheric cooling component of TMT. This method has been validated with both observed and model atmospheric temperature data $[41,63,64$. Here, we refer to the corrected version of TMT as $\mathrm{TMT}_{c r}$. The main text discusses corrected TMT only, and does not use the subscript $c r$ to identify corrected TMT.

For calculating tropical averages of $\mathrm{TMT}_{c r}$, ref. [61] used:

$$
\mathrm{TMT}_{c r}=a_{24} \mathrm{TMT}+\left(1-a_{24}\right) \mathrm{TLS}
$$

where $a_{24}=1.1$. For the near-global domain considered here, lower stratospheric cooling makes a larger contribution to TMT trends, so $a_{24}$ is larger [40, 62]. In refs. [40] and [62], $a_{24} \approx 1.15$ was applied directly to near-global averages of TMT and TLS. Since we are performing corrections on local (grid-point) data, we used $a_{24}=$ 1.1 between $30^{\circ} \mathrm{N}$ and $30^{\circ} \mathrm{S}$, and $a_{24}=1.2$ poleward of $30^{\circ}$. This is approximately equivalent to use of the $a_{24}=1.15$ for globally-averaged data. 


\section{Details of model output}

We used model output from phase 5 of the Coupled Model Intercomparison Project (CMIP5) [39]. The simulations analyzed here were contributed by 19 different research groups (see Supplementary Table S1). Our focus was on three different types of numerical experiment: 1) simulations with estimated historical changes in human and natural external forcings; 2) simulations with 21st century changes in greenhouse gases and anthropogenic aerosols prescribed according to the Representative Concentration Pathway 8.5 (RCP8.5), with radiative forcing of approximately 8.5 $\mathrm{W} / \mathrm{m}^{2}$ in 2100 , eventually stabilizing at roughly $12 \mathrm{~W} / \mathrm{m}^{2}$; and 3 ) pre-industrial control runs with no changes in external influences on climate.

Most CMIP5 historical simulations end in December 2005. RCP8.5 simulations were typically initiated from conditions of the climate system at the end of the historical run. To avoid truncating comparisons between modeled and observed atmospheric temperature trends in December 2005, we spliced together synthetic satellite temperatures from the historical simulations and the RCP8.5 runs. Splicing allows us to compare actual and synthetic temperature changes over the full 38-year length of the satellite record. We use the acronym "HIST +8.5 " to identify these spliced simulations. Some issues related to splicing are discussed in the Supplementary Information.

Supplementary Table S2 provides information on the external forcings in the CMIP5 historical simulations. Details of the start dates, end dates, and lengths of the 
historical integrations and RCP8.5 runs are given in Supplementary Table S3. Corresponding information for the pre-industrial control runs is supplied in Supplementary Table S4. In total, we analyzed 49 individual HIST +8.5 realizations performed with 37 different CMIP5 models. Our climate noise estimates rely on pre-industrial control runs from 36 CMIP5 models.

\section{Calculation of synthetic satellite temperatures}

We use a local weighting function method developed at RSS to calculate synthetic satellite temperatures from model output [54]. At each model grid-point, simulated temperature profiles were convolved with local weighting functions. The weights depend on the grid-point surface pressure, the surface type (land or ocean), and the selected layer-average temperature (TLS, TMT, or TLT).

\section{Statistical analysis}

We analyze the statistical significance of trends in the temperature difference time series $\Delta T_{f-o}(k, t)$ :

$$
\begin{array}{r}
\Delta T_{f-o}(k, t)=\overline{\bar{T}}_{f}(t)-T_{o}(k, t) \\
k=1, \ldots, N_{o b s} ; \quad t=1, \ldots, N_{t}
\end{array}
$$


470

where $\overline{\bar{T}}_{f}(t)$ is the multi-model average atmospheric temperature time series calculated from the forced HIST +8.5 simulations, and $T_{o}(k, t)$ is the temperature time series of the $k^{t h}$ observational dataset. Positive (negative) trends in $\Delta T_{f-o}(k, t)$ indicate model-average tropospheric warming that is larger (smaller) than observed. We seek to determine whether internal variability alone can explain large differences between expected and observed warming rates (both positive and negative).

All trends are calculated with monthly-mean TMT or TLT data. Rather than focusing on one specific period or timescale, we perform a comprehensive analysis of difference series trends on timescales ranging from 10 to 18 years, in increments of two years. These are typical record lengths used for study of the "warming slowdown" in the early 21st century [16, 19].

Our analysis relies on maximally overlapping trends. "Maximally overlapping" indicates that an $L$-year sliding window is used for trend calculations. This window advances in increments of one month until the end of the current window reaches the final month of the $\Delta T_{f-o}(k, t)$ difference series.

In calculating the HIST +8.5 multi-model average (MMA), we specify that $j$ is a combined index over models and HIST +8.5 realizations. The first averaging step is over HIST +8.5 realizations, and the second is over models. For processing the pre-industrial control runs, each model has only one control run, so $j$ is an index over the number of models only. 
498

Anomalies in the satellite observations and HIST +8.5 runs were defined relative to climatological monthly means calculated over the 38-year period from January 1979 to December 2016. Control run anomalies were defined relative to climatological monthly means over the full length of each model's control integration.

\section{Calculating p-values for individual difference series trends}

We assess trend significance using weighted $p$-values, which account for inter-model differences in control run length [45].

The weighted $p$-value, $\overline{p_{c}}(i, k, l)^{\prime}$, is defined as:

$$
\overline{p_{c}}(i, k, l)^{\prime}=\sum_{j=1}^{N_{\text {model }}} p_{c}(i, j, k, l) / N_{\text {model }}
$$

$$
i=1, \ldots, N_{f-o}(l) ; j=1, \ldots, N_{\text {model }} ; \quad k=1, \ldots, N_{\text {obs }} ; \quad l=1, \ldots, N_{L}
$$

where $i$ is over $N_{f-o}(l)$, the total number of maximally overlapping $L$-year trends in $\Delta T_{f-o}(k, t) ; j$ is over $N_{\text {model }}$, the number of model control runs; $k$ is over $N_{o b s}$, the total number of satellite datasets; and $l$ is over $N_{L}$, the number of values of the trend length $L$. Here, $N_{f-o}(l)=337$ for 10-year (120-month) trends; $N_{\text {model }}=36 ; N_{\text {obs }}=6$; and $N_{L}=5(10,12,14,16$, and 18 years $)$.

The individual $p_{c}(i, j, k, l)$ values for each model pre-industrial control run are calcu- 
$i=1, \ldots, N_{f-o}(l) ; j=1, \ldots, N_{\text {model }} ; \quad k=1, \ldots, N_{\text {obs }} ; \quad l=1, \ldots, N_{L}$

lated as follows:

$$
p_{c}(i, j, k, l)=K_{c}(i, j, k, l) / N_{c}(j, l)
$$

where $K_{c}(i, j, k, l)$ is the number of $L$-year trends in the $j^{t h}$ pre-industrial control run (for the $l^{\text {th }}$ value of the trend length $L$ ) that are larger than the current $L$-year trend in $\Delta T_{f-o}(k, t)$. The sample size $N_{c}(j, l)$ is the number of maximally overlapping $L$-year trends in the $j^{\text {th }}$ control run.

Use of maximally overlapping trends has the advantage of reducing the impact of seasonal and interannual noise on atmospheric temperature trends, both in the $\Delta T_{f-o}(k, t)$ difference series and in the control runs. It has the disadvantage of decreasing the statistical independence of trend samples. Non-independence of samples is an important issue in formal statistical significance testing, but is not a serious concern here. This is because $\overline{p_{c}}(i, k, l)^{\prime}$ is not used as a basis for formal statistical tests. Instead, it simply provides useful information on whether trends in $\Delta T_{f-o}(k, t)$ are unusually large or small relative to model estimates of unforced trends.

\section{Calculating actual values of asymmetry statistics}

The $p$-values in the right-hand column of Fig. 2 reveal pronounced asymmetries. Three asymmetries are of interest here. 
The first type of asymmetric behavior relates to the numbers of significant positive and significant negative trends. For each analysis timescale in Fig. 2, the overlapping trends computed from the $\Delta T_{f-o}(k, t)$ difference series display a preponderance of significant positive results. We use the $\gamma_{1}$ statistic to quantify this asymmetry:

$$
\gamma_{1}(k, l)=K_{+v e}(k, l)-K_{-v e}(k, l)
$$

where

$$
\begin{aligned}
K_{+v e}(k, l) & =\sum_{i=1}^{N_{f-o}(l)} M(i, k, l) \\
M(i, k, l) & =1 \text { if } \quad \bar{p}_{c}(i, k, l)^{\prime} \leq 0.1 \\
M(i, k, l) & =0 \text { if } \quad \bar{p}_{c}(i, k, l)^{\prime}>0.1
\end{aligned}
$$

and

$$
\begin{aligned}
& K_{-v e}(k, l)=\sum_{i=1}^{N_{f-o}(l)} M(i, k, l) \\
& M(i, k, l)=1 \text { if } \quad \overline{p_{c}}(i, k, l)^{\prime} \geq 0.9 \\
& M(i, k, l)=0 \text { if } \quad \overline{p_{c}}(i, k, l)^{\prime}<0.9
\end{aligned}
$$

The summation variables $K_{+v e}(k, l)$ and $K_{-v e}(k, l)$ in equation (6) are the total numbers of significant positive and significant negative trends in $\Delta T_{f-o}(k, t)$ (respectively). $M(i, k, l)$ in equations (7) and (8) is an integer counter, and $\overline{p_{c}}(i, k, l)^{\prime}$ is the weighted $p$-value for the current maximally overlapping trend, satellite dataset, and trend length. The significance of individual trends is assessed at the $10 \%$ level. 
asymmetry is unusual:

$$
\gamma_{2}(k, l)=K_{\mathrm{SET} 1}(k, l)-K_{\mathrm{SET} 2}(k, l)
$$

where

$$
\begin{aligned}
K_{\mathrm{SET} 1}(k, l) & =\sum_{i=1}^{N(l)} M(i, k, l) \\
M(i, k, l) & =1 \text { if } \overline{p_{c}}(i, k, l)^{\prime} \leq 0.1 \\
M(i, k, l) & =0 \text { if } \overline{p_{c}}(i, k, l)^{\prime}>0.1 \\
N(l) & =\left[N_{f-o}(l)-1\right] / 2
\end{aligned}
$$

and

$$
\begin{aligned}
K_{\mathrm{SET} 2}(k, l) & =\sum_{i=N(l)+1}^{N_{f-o}(l)} M(i, k, l) \\
M(i, k, l) & =1 \text { if } \overline{p_{c}}(i, k, l)^{\prime} \leq 0.1 \\
M(i, k, l) & =0 \text { if } \overline{p_{c}}(i, k, l)^{\prime}>0.1
\end{aligned}
$$

The $\gamma_{3}$ statistic is analogous to $\gamma_{2}$, but relies on differences between the average values of $\overline{p_{c}}(i, k, l)^{\prime}$ in SET 1 and SET 2 :

$$
\gamma_{3}(k, l)=\overline{\overline{p_{c_{1}}}}(k, l)^{\prime}-\overline{\overline{p_{c_{2}}}}(k, l)^{\prime}
$$

where the average SET 1 and SET $2 p$-values, $\overline{\overline{p_{c_{1}}}}(k, l)^{\prime}$ and $\overline{\overline{p_{c_{2}}}}(k, l)^{\prime}$, are given by: 


$$
\begin{aligned}
\overline{\overline{p_{c_{1}}}}(k, l)^{\prime} & =\sum_{i=1}^{N(l)} \overline{p_{c}}(i, k, l)^{\prime} / N(l) \\
\overline{\overline{p_{c_{2}}}}(k, l)^{\prime} & =\sum_{i=N(l)+1}^{N_{f-o}(l)} \overline{p_{c}}(i, k, l)^{\prime} / N(l) \\
N(l) & \approx N_{f-o}(l) / 2
\end{aligned}
$$

Unlike $\gamma_{1}$ and $\gamma_{2}$, the $\gamma_{3}$ statistic is not sensitive to the selected level for assessing the significance of individual trends in $\Delta T_{f-o}(k, t)$.

\section{Overall significance of asymmetry statistics}

To determine the significance of the actual values of these asymmetry statistics, we require null distributions of $\gamma_{1}, \gamma_{2}$ and $\gamma_{3}$, where we know a priori that changes in the statistics are solely due to random realizations of natural internal variability. We obtain null distributions of $\gamma_{1}, \gamma_{2}$ and $\gamma_{3}$ using surrogate observational temperature time series from the CMIP5 control runs. The processing steps are as follows:

1. Randomly select one of the 36 CMIP5 pre-industrial control runs.

2. From the selected control run, randomly choose the initial month of a 456-month segment of temperature anomaly data. Ensure that the selected initial month is valid (i.e., that there are still at least 455 months between the selected initial month and the end of the current control run). If this condition is not satisfied, 
continue random selection of an initial month until the first valid month is obtained. The time series of surrogate observations is comprised of the first valid month and the next 455 months.

3. With the current surrogate observational time series, $T_{\text {surr }}(m, t)$, calculate the weighted $p$-values, $\overline{p_{c}}(i, k, l)^{\prime}$, as in equation (3). Since we are interested in how $\gamma_{1}, \gamma_{2}$ and $\gamma_{3}$ behave in the presence of natural variability alone, the surrogate observations are not used to form a difference series - i.e., they are not subtracted from $\overline{\bar{T}}_{f}(t)$ (the multi-model average), as was the case with the actual satellite temperature data. Instead, individual maximally overlapping $L$-year trends in the surrogate observations are compared directly with distributions of control run $L$-year trends. In computing $\overline{p_{c}}(i, k, l)^{\prime}$, the current surrogate observational time series is excluded from the control runs used to calculate unforced $L$-year temperature trends, and the summation in equation (3) is over $N_{\text {model }}-1$ rather than over $N_{\text {model }}$.

4. From the values of $\overline{p_{c}}(i, k, l)^{\prime}$ obtained from step 3, calculate the asymmetry statistics $\gamma_{1}, \gamma_{2}$ and $\gamma_{3}$, as in equations (5), (8), and (11).

5. Store these asymmetry statistics in $\gamma_{1}(l, m)^{*}, \gamma_{2}(l, m)^{*}$ and $\gamma_{3}(l, m)^{*}$, where the index $m$ is over the total number of time series of randomly selected surrogate observations, and * denotes a statistic calculated with surrogate observational temperature data. 
6. Return to step 1; repeat steps 1 through 5 until 5,000 surrogate observational time series have been selected, and 5,000-member distributions of $\gamma_{1}(l, m)^{*}$, $\gamma_{2}(l, m)^{*}$ and $\gamma_{3}(l, m)^{*}$ have been generated.

7. For each observational dataset, and for each of the five trend lengths considered $(10,12, \ldots 18$ years $)$, compare the actual values of $\gamma_{1}(k, l), \gamma_{2}(k, l)$ and $\gamma_{3}(k, l)$ with their corresponding null distributions - i.e., with $\gamma_{1}(l, m)^{*}, \gamma_{2}(l, m)^{*}$ and $\gamma_{3}(l, m)^{*}$, respectively. Examples of such comparisons are shown in Figs. 3B, D, and $\mathrm{F}$ of the main text for the case of 10 -year trends. Determine the probability that the actual values of $\gamma_{1}(k, l), \gamma_{2}(k, l)$ and $\gamma_{3}(k, l)$ could be due to internal variability alone. These overall probabilities are $p_{\gamma_{1}}(k, l), p_{\gamma_{2}}(k, l)$ and $p_{\gamma_{3}}(k, l)$.

\section{"Perfect model" results}

Our "perfect model" analysis considers whether an error in model Equilibrium Climate Sensitivity (ECS), coupled with different phasing of internal climate variability in the real world and in model HIST+8.5 simulations, could plausibly explain the actual values of the three asymmetry statistics. To address this question, we form difference series between tropospheric temperature changes in the HIST+8.5 MMA and in individual model realizations of HIST +8.5 :

$$
\Delta T_{f-f}(j, t)=\overline{\bar{T}}_{f}(t)-T_{f}(j, t)
$$




$$
j=1, \ldots, N_{\text {model }} ; \quad t=1, \ldots, N_{t}
$$

where $j$ is an combined index over HIST +8.5 realizations and models used to perform the HIST+8.5 simulation. We calculate $\Delta T_{f-f}(j, t)$ for six different non-overlapping 456-month periods: the same January 1979 to December 2016 period used for computing the "MMA minus observed" difference series in equation (2), three earlier periods (1862 to 1899, 1900 to 1937, and 1940 to 1977), and two later periods (2020 to 2057 and 2058 to 2095). Because two of the three HadGEM2-CC HIST+8.5 realizations commence in December 1959, the sample size is not identical for the six analysis periods: $N_{\text {model }}=47$ (49) for the first three (last three) periods, yielding a total number of $288 \Delta T_{f-f}(j, t)$ time series from which asymmetry statistics can be calculated.

We process these 288 "MMA minus individual model" difference time series in the same way we treat the "MMA minus observed" difference series - i.e., we fit maximally overlapping $L$-year trends to each $\Delta T_{f-f}(j, t)$ series, estimate weighted $p$-values for each overlapping trend (by comparing with control run distributions of unforced $L$-year trends), and then use these $p$-values to calculate asymmetry statistics. The resulting "perfect model" asymmetry statistics are $\gamma_{1}(j, l), \gamma_{2}(j, l)$ and $\gamma_{3}(j, l)$; the statistics are indexed over HIST +8.5 realizations and models (the $j$ index) and over the number of values of the trend timescale (the $l$ index). Distributions of these statistics are shown in Supplementary Fig. S9 for the 10-year analysis timescale. 
607

\section{Proxy for ECS}

ECS information is typically obtained from a $4 \times \mathrm{CO}_{2}$ simulation [65]. Not all modeling groups participating in CMIP5 performed this simulation. Here, we have ECS information for only 23 of the 37 CMIP5 models employed in our "perfect model" analysis. To study underlying relationships between Equilibrium Climate Sensitivity (ECS) and the "perfect model" results, we require a proxy for ECS. Our selected proxy is $\Delta T_{8.5}$, the total linear change in near-global averages of corrected TMT in the RCP8.5 simulation. For each realization and model, $\Delta T_{8.5}$ is calculated over the 1,080-month period from January 2006 to December 2095 - the longest common period in the RCP8.5 simulations analyzed here (see Supplementary Table S3). For the 23 models with $4 \times \mathrm{CO}_{2}$ simulations, ECS is highly correlated with $\Delta T_{8.5}$ (Supplementary Fig. S6). This provides justification for our use of $\Delta T_{8.5}$ as an ECS proxy in Supplementary Fig. S7. For the models analyzed here, $\Delta T_{8.5}$ ranges from $3.28^{\circ} \mathrm{C}$ in GISS-E2-R (p1) to $6.28^{\circ} \mathrm{C}$ in GFDL-CM3.

\section{Sample sizes in tests of asymmetry statistics}

In assessing the statistical significance of our asymmetry statistics, we have greater confidence in our ability to rule out internal variability than in our ability to rule out the combined effects of internal variability and a model sensitivity error. This is because the sample size used to test the "internal variability only" explanation 
626

627

628

(5,000 time series of surrogate observations) is much larger than the sample size in the "perfect model" analysis (288 time series of differences between the MMA and individual model HIST +8.5 realizations). The analysis using surrogate observations explores a much larger phase space in the timing and amplitude of the IPO and other modes of internal variability.

\section{Author contributions}

B.D.S., J.C.F., G.P., G.M.F., and E.H. designed the analysis. B.D.S. performed all statistical analyses. J.F.P. calculated synthetic satellite temperatures from model simulation output and provided assistance with processing of observed temperature data. C.M., F.J.W., S.P.-C., Q.F., and C.-Z.Z. provided satellite temperature data. I.C., C.B., and J.F.P. assisted with the processing of the CMIP5 simulations analyzed here. All authors contributed to the writing and review of the manuscript.

\section{Competing financial interests}

The authors declare no competing financial interests.

Corresponding author

Correspondence should be sent to B. D. Santer (santer1@llnl.gov). 


\section{${ }_{642}$ References}

[1] IPCC. Summary for Policymakers. In T. F. Stocker, D. Qin, G.-K. Plattner, M. Tignor, S. K. Allen, J. Boschung, A. Nauels, Y. Xia, V. Bex, and P. M. Midgley, editors, Climate Change 2013: The Physical Science Basis. Contribution of Working Group I to the Fifth Assessment Report of the Intergovernmental Panel on Climate Change. Cambridge University Press, 2013. 29 pages.

[2] G. Flato, J. Marotzke, B. Abiodun, P. Braconnot, S. C. Chou, W. Collins, P. Cox, F. Driouech, S. Emori, V. Eyring, C. Forest, P. Gleckler, E. Guilyardi, C. Jakob, V. Kattsov, C. Reason, and M. Rummukainen. Evaluation of climate models. In T. F. Stocker, D. Qin, G.-K. Plattner, M. Tignor, S. K. Allen, J. Boschung, A. Nauels, Y. Xia, V. Bex, and P. M. Midgley, editors, Climate Change 2013: The Physical Science Basis. Contribution of Working Group I to the Fifth Assessment Report of the Intergovernmental Panel on Climate Change, pages 741-866. Cambridge University Press, 2013.

[3] T. R. Karl, A. Arguez, B. Huang, J. H. Lawrimore, J. R. McMahon, M. J. Menne, T. C. Peterson, R. S. Vose, and H.-M. Zhang. Possible artifacts of data biases in the recent global surface warming hiatus. Science, 348:1469-1472, 2015.

[4] K. Cowtan, Z. Hausfather, E. Hawkins, P. Jacobs, M. E. Mann, S. K. Miller, B. A. Steinman, M. B. Stolpe, and R. G. Way. Robust comparison of climate models 
with observations using blended land air and ocean sea surface temperatures. Geophys. Res. Lett., 42(15):6526-6534, 2015.

[5] Z. Hausfather, K. Cowtan, D. C. Clarke, P. Jacobs, M. Richardson, and R. Rohde. Assessing recent warming using instrumentally homogeneous sea surface temperature records. Sci. Adv., 3, e1601207, 2017.

[6] S. Lewandowsky, J. S. Risbey, and N. Oreskes. The "pause" in global warming: Turning a routine fluctuation into a problem for science. Bull. Amer. Meteor. Soc., 97(5):723-733, 2016.

[7] N. Cahill, S. Rahmstorf, and A. C. Parnell. Change points of global temperature. Environ. Res. Lett., 10, 084002, 2015.

[8] B. Rajaratnam, J. Romano, M. Tsiang, and N. S. Diffenbaugh. Debunking the climate hiatus. Clim. Change, 133:129-140, 2015.

[9] S. Rahmstorf, G. Foster, and N. Cahill. Global temperature evolution: recent trends and some pitfalls. Env. Res. Lett., 12, 2017.

[10] Y. Kosaka and S.-P. Xie. Recent global-warming hiatus tied to equatorial Pacific surface cooling. Nature, 501:403-407, 2013.

[11] G. A. Meehl, H. Teng, and J. M. Arblaster. Climate model simulations of the observed early-2000s hiatus of global warming. Nat. Clim. Change, 4:898-902, 2014. 
[12] J. S. Risbey, S. Lewandowsky, C. Langlais, D. P. Monselesan, T. J. O'Kane, and N. Oreskes. Well-estimated global surface warming in climate projections selected for ENSO phase. Nat. Clim. Change, 4:835-840, 2014.

[13] M. H. England, S. McGregor, P. Spence, G. A. Meehl, A. Timmermamm, W. Cai, A. Sen Gupta, M. J. McPhaden, A. Purich, and A. Santoso. Recent intensification of wind-driven circulation in the Pacific and the ongoing warming hiatus. Nat. Clim. Change, 4:222-227, 2014.

[14] B. A. Steinman, M. E. Mann, and S. K. Miller. Atlantic and Pacific multidecadal oscillations and Northern Hemisphere temperatures. Science, 347:988-991, 2015.

[15] B. D. Santer, C. Bonfils, J. Painter, M. Zelinka, C. Mears, S. Solomon, G. A. Schmidt, J. C. Fyfe, J. N. S. Cole, L. Nazarenko, K. E. Taylor, and F. J. Wentz. Volcanic contribution to decadal changes in tropospheric temperature. Nat. Geosci., 7:185-189, 2014.

[16] J. C. Fyfe, G. A. Meehl, M. H. England, M. E. Mann, B. D. Santer, G. M. Flato, E. Hawkins, N. P. Gillett, S.-P. Xie, Y. Kosaka, and N. C. Swart. Making sense of the early-2000s warming slowdown. Nat. Clim. Change, 6:224-228, 2016.

[17] G. A. Schmidt, D. T. Shindell, and K. Tsigaridis. Reconciling warming trends. Nat. Geosci., 7:1-3, 2014. 
[18] H. Gleisner, P. Thejll, B. Christianson, and J. K. Nielsen. Recent global warming hiatus dominated by low-latitude temperature trends in surface and troposphere data. Geophys. Res. Lett., 42:510-517, 2014.

[19] I. Medhaug, M. B. Stolpe, E. M Fischer, and R. Knutti. Reconciling controversies about the 'global warming hiatus'. Nature, 545:41-47, 2017.

[20] S. Solomon, J. S. Daniel, R. R. Neely, J.-P. Vernier, E. G. Dutton, and L. W. Thomason. The persistently variable "background" stratospheric aerosol layer and global climate change. Science, 333:866-870, 2011.

[21] J.-P. Vernier, L. W. Thomason, J.-P. Pommereau, A. Bourassa, J. Pelon, A. Garnier, A. Hauchecorne, L. Blanot, C. Trepte, D. Degenstein, and F. Vargas. Major influence of tropical volcanic eruptions on the stratospheric aerosol layer during the last decade. Geophys. Res. Lett., 38, 2011. http://dx.doi.org/10.1029/2011GL047563.

[22] R. R. Neely, O. B. Toon, S. Solomon, J.-P. Vernier, C. Alvarez, J. M. English, K. H. Rosenlof, M. J. Mills, C. G. Bardeen, J. S. Daniel, and J. P. Thayer. Recent anthropogenic increases in $\mathrm{SO}_{2}$ from Asia have minimal impact on stratospheric aerosol. Geophys. Res. Lett., 40:1-6, 2013.

[23] D. A. Ridley, S. Solomon, J. E. Barnes, V. D. Burlakov, T. Deshler, S. I. Dolgii, A. B. Herber, T. Nagai, R. R. Neely III, A. V. Nevzorov, C. Ritter, T. Sakai, B. D. Santer, M. Sato, A. Schmidt, O. Uchino, and J.-P. Vernier. Total volcanic 
stratospheric aerosol optical depths and implications for global climate change. Geophys. Res. Lett., 41:7763-7769, 2014.

[24] B. D. Santer, S. Solomon, C. Bonfils, M. D. Zelinka, J. F. Painter, F. Beltran, J. C. Fyfe, G. Johannesson, C. Mears, D. A. Ridley, J.-P. Vernier, and F. J. Wentz. Observed multivariable signals of late 20th and early 21st century volcanic activity. Geophys. Res. Lett., 42:500-509, 2015.

[25] G. Kopp and J. L. Lean. A new, lower value of total solar irradiance: Evidence and climate significance. Geophys. Res. Lett., 38, 2011. http://dx.doi.org/10.1029/2010GL045777.

[26] D. M. Smith, B. B. B. Booth, N. J. Dunstone, R. Eadie, L. Hermanson, G. S. Jones, A. A. Scaife, K. L. Sheen, and V. Thompson. Role of volcanic and anthropogenic aerosols in the recent global surface warming slowdown. Nat. Clim. Change, 6:936-940, 2016.

[27] S. Solomon, K. H. Rosenlof, R. W. Portman, J. S. Daniel, S. M. Davis, T. J. Sanford, and G.-K. Plattner. Contributions of stratospheric water vapor to decadal changes in the rate of global warming. Science, 327:1219-1223, 2010.

[28] J. R. Christy. Testimony in Hearing before the U.S. Senate Committee on Commerce, Science, and Transportation, Subcommittee on Space, Science, and Competitiveness, December 8, 2015, 2015. [Available online at http://www. commerce.senate.gov/public/index.cfm/2015/12/data-or-dogma-pro 
moting-open-inquiry-in-the-debate-over-the-magnitude-of-human-

impact-on-earth-s-climate.

[29] C. Mears and F. J. Wentz. Sensitivity of satellite-derived tropospheric temperature trends to the diurnal cycle adjustment. J. Clim., 29:3629-3646, 2016.

[30] S. Po-Chedley, T. J. Thorsen, and Q. Fu. Removing diurnal cycle contamination in satellite-derived tropospheric temperatures: Understanding tropical tropospheric trend discrepancies. J. Clim., 28:2274-2290, 2015.

[31] C.-Z. Zou and W. Wang. Inter-satellite calibration of AMSU-A observations for weather and climate applications. J. Geophys. Res., 116, 2011. http://dx.doi.org/10.1029/2011JD016205.

[32] K. Cowtan and R. G. Way. Coverage bias in the HadCRUT4 temperature series and its impact on recent temperature trends. Quart. J. Roy. Met. Soc., 140:1935$1944,2014$.

[33] US Senate. Data or Dogma? Promoting open inquiry in the debate over the magnitude of human impact on Earth's climate. Hearing before the U.S. Senate Committee on Commerce, Science, and Transportation, Subcommittee on Space, Science, and Competitiveness, One Hundred and Fourteenth Congress, first session, December 8, 2015. https:clio.columbia.edu/catalog/12267036. 
[34] J. R. Christy, W. B. Norris, R. W. Spencer, and J. J. Hnilo. Tropospheric temperature change since 1979 from tropical radiosonde and satellite measurements. J. Geophys. Res., 112, 2007. http://dx.doi.org/10.1029/2005JD006881.

[35] P. Bloomfield and D. Nychka. Climate spectra and detecting climate change. Clim. Change, 21:275-287, 1992.

[36] P. T. Brown, W. Li, E. C. Cordero, and S. A. Mauget. Comparing the modelsimulated global warming signal to observations using empirical estimates of unforced noise. Nature Sci. Rep., 5, 9957, 2016.

[37] M. R. Allen and S. F. B. Tett. Checking for model consistency in optimal fingerprinting. Cli. Dyn., 15:419-434, 1999.

[38] M. E. Mann, S. Rahmstorf, B. A. Steinman, M. Tingley, and S. K. Miller. The likelihood of recent warmth. Nat. Sci. Rep., 6, 19831, 2016.

[39] K. E. Taylor, R. J. Stouffer, and G. A. Meehl. An overview of CMIP5 and the experiment design. Bull. Amer. Meteor. Soc., 93:485-498, 2012.

[40] Q. Fu, C. M. Johanson, S. G. Warren, and D. J. Seidel. Contribution of stratospheric cooling to satellite-inferred tropospheric temperature trends. Nature, 429:55-58, 2004.

[41] Q. Fu and C. M. Johanson. Stratospheric influences on MSU-derived tropospheric temperature trends: A direct error analysis. J. Clim., 17:4636-4640, 2004. 
[42] Q. Fu, S. Manabe, and C. M. Johanson. On the warming in the tropical upper troposphere: Models versus observations. Geophys. Res. Lett., 38, 2011. http://dx.doi.org/10.1029/2011GL048101.

[43] S. Po-Chedley and Q. Fu. Discrepancies in tropical upper tropospheric warming between atmospheric circulation models and satellites. Environ. Res. Lett., 7, 2012. http://dx.doi.org/10.1088/1748-9326/7/4/044018.

[44] B. D. Santer, C. Mears, C. Doutriaux, P. Caldwell, P. J. Gleckler, T. M. L. Wigley, S. Solomon, N. P. Gillett, D. Ivanova, T. R. Karl, J. R. Lanzante, G. A. Meehl, P. A. Stott, K.E. Taylor, P. W. Thorne, M. F. Wehner, and F. J. Wentz. Separating signal and noise in atmospheric temperature changes: The importance of timescale. J. Geophys. Res., 116, 2011. http://dx.doi.org/10.1029/2011JD016263.

[45] B. D. Santer, S. Solomon, G. Pallotta, C. Mears, S. Po-Chedley, Q. Fu, F. Wentz, C.-Z. Zou, J. Painter, I. Cvijanovic, and C. Bonfils. Comparing tropospheric warming in climate models and satellite data. J. Clim., 30:373-392, 2017.

[46] T. M. L. Wigley, C. M. Ammann, B. D. Santer, and S. C. B. Raper. The effect of climate sensitivity on the response to volcanic forcing. J. Geophys. Res., 110, 2005. http://dx.doi.org/10.1029/2004/JD005557.

[47] J. C. Fyfe, N. P. Gillett, and F. W. Zwiers. Overestimated global warming over the past 20 years. Nat. Clim. Change, 3:767-769, 2013. 
[48] D. J. A. Johansson, B. C. O'Neill, C. Tebaldi, and O. Häggström. Equilibrium climate sensitivity in light of observations over the warming hiatus. Nat. Clim. Change, 5:449-453, 2015.

[49] F. J. Wentz and M. Schabel. Effects of orbital decay on satellite-derived lowertropospheric temperature trends. Nature, 394:661-664, 1998.

[50] C. A. Mears, M. C. Schabel, and F. J. Wentz. A reanalysis of the MSU channel 2 tropospheric temperature record. J. Clim., 16:3650-3664, 2003.

[51] S. Po-Chedley and Q. Fu. A bias in the mid-tropospheric channel warm target factor on the NOAA-9 Microwave Sounding Unit. J. Atmos. Oceanic Technol., 29:646-652, 2012.

[52] K. E. Trenberth. Has there been a hiatus? Science, 349:791-792, 2015.

[53] X. Chen and K. K. Tung. Varying planetary heat sink led to global-warming slowdown and acceleration. Science, 345:897-903, 2014.

[54] B. D. Santer, J. F. Painter, C. A. Mears, C. Doutriaux, P. Caldwell, J. M. Arblaster, P. J. Cameron-Smith, N. P. Gillett, P. J. Gleckler, J. Lanzante, J. Perlwitz, S. Solomon, P. A. Stott, K. E. Taylor, L. Terray, P. W. Thorne, M. F. Wehner, F. J. Wentz, T. M. L. Wigley, L. J. Wilcox, and C.-Z. Zou. Identifying human influences on atmospheric temperature. Proc. Nat. Acad. Sci., 110:26-33, 2013. 
[55] J. Imbers, A. Lopez, C. Huntingford, and M. R. Allen. Testing the robustness of anthropogenic climate change detection statements using different empirical models. J. Geophys. Res., 118:3192-3199, 2013.

[56] T. M. L. Wigley and S. C. B. Raper. Natural variability of the climate system and detection of the greenhouse effect. Nature, 344:324-327, 1990.

[57] B. J. Henley, G. Meehl, S. B. Power, C. K. Folland, A. D. King, J. N. Brown, D. J. Karoly, F. Delage, A. J. E. Gallant, M. Freund, and R. Neukom. Spatial and temporal agreement in climate model simulations of the interdecadal pacific oscillation. Env. Res. Lett., 12, 2017.

[58] C. Mears, F. J. Wentz, P. Thorne, and D. Bernie. Assessing uncertainty in estimates of atmospheric temperature changes from MSU and AMSU using a Monte-Carlo technique. J. Geophys. Res., 116, 2011. http://dx.doi.org/10.1029/2010JD014954.

[59] C.-Z. Zou, M. D. Goldberg, Z. Cheng, N. C. Grody, J. T. Sullivan, C. Cao, and D. Tarpley. Recalibration of microwave sounding unit for climate studies using simultaneous nadir overpasses. J. Geophys. Res., 111, 2006. http://dx.doi.org/10.1029/2005JD006798.

[60] C.-Z. Zou, M. Gao, and M. Goldberg. Error structure and atmospheric temperature trends in observations from the Microwave Sounding Unit. J. Clim., $22: 1661-1681,2009$. 
[61] Q. Fu and C. M. Johanson. Satellite-derived vertical dependence of tropical tropospheric temperature trends. Geophys. Res. Lett., 32, 2005. http://dx.doi.org/10.1029/2004GL022266.

[62] C. M. Johanson and Q. Fu. Robustness of tropospheric temperature trends from MSU Channels 2 and 4. J. Clim., 19:4234-4242, 2006.

[63] N. P. Gillett, B. D. Santer, and A. J. Weaver. Quantifying the influence of stratospheric cooling on satellite-derived tropospheric temperature trends. Nature, 432, 2004. http://10.1038/nature03209.

[64] J. T. Kiehl, J. Caron, and J. J. Hack. On using global climate model simulations to assess the accuracy of MSU retrieval methods for tropospheric warming trends. J. Clim., 18:2533-2539, 2005.

[65] T. Andrews, J. M. Gregory, M. J. Webb, and K. E. Taylor. Forcing, feedbacks and climate sensitivity in CMIP5 coupled atmosphere-ocean climate models. Geophys. Res. Lett., 39, 2012. http://10.1029/2012GL051607.

\section{Acknowledgments}

We acknowledge the World Climate Research Programme's Working Group on Coupled Modelling, which is responsible for CMIP, and we thank the climate modelling groups for producing and making available their model output. For CMIP, the U.S. 
852

853

854

Department of Energy's Program for Climate Model Diagnosis and Intercomparison (PCMDI) provides coordinating support and led development of software infrastructure in partnership with the Global Organization for Earth System Science Portals. We thank Mark Zelinka (PCMDI) for providing CMIP5 climate sensitivity results, Susan Solomon (M.I.T.) for helpful discussions, and three anonymous reviewers for constructive comments. The views, opinions, and findings contained in this report are those of the authors and should not be construed as a position, policy, or decision of the U.S. Government, the U.S. Department of Energy, or the National Oceanic and Atmospheric Administration. 
Figure 1: Time series (panel A) and difference series (panel B) of simulated and observed tropospheric temperature. Results are monthly-mean TMT anomalies for the 456-month period from January 1979 to December 2016, spatially averaged over $82.5^{\circ} \mathrm{N}-82.5^{\circ} \mathrm{S}$ and corrected for lower stratospheric cooling [40]. Multi-model average (MMA) temperature data are from HIST+8.5 simulations performed with 37 different CMIP5 models; satellite TMT data are for RSS version 4.0 [29]. Model TMT data were computed using vertical weighting functions that approximate the satellite-based vertical sampling of the atmosphere [54]. The time series of differences between the MMA and the RSS data is shown in both raw form and smoothed with a 12-month running mean (panel B). All anomalies are relative to climatological monthly means calculated over January 1979 to December 2016. The vertical purple line is plotted at the time of the maximum global-mean tropospheric warming during the $1997 / 98 \mathrm{El}$ Niño. The vertical green lines denote the eruption dates of El Chichón and Pinatubo. Trends in the MMA and RSS over the full 456 months (the grey and pink lines in panel A) are 0.291 and $0.199^{\circ} \mathrm{C} /$ decade, respectively. The corresponding trends over the early 21st century (January 2000 to December 2016 ) are 0.286 and $0.191^{\circ} \mathrm{C} /$ decade.

Figure 2: Trends (left column) and trend significance (right column) for TMT difference series. The six difference series are for near-global averages of corrected TMT, and were computed by subtracting each of the six individual satellite TMT records from the HIST+8.5 multi-model average TMT time series (see Fig. 1). Maximally overlapping trends were fit to each 456-month difference series. Results are for trend 
lengths of $L=10,12,14,16$, and 18 years; the overlap between successive $L$-year trends is by all but one month. The $p$-values associated with each $L$-year difference series trend were obtained by testing against multi-model distributions of unforced L-year TMT trends from 36 different CMIP5 control runs. Results are plotted on the last month of the trend-fitting period. Grey shading denotes the rejection region (at a stipulated $10 \%$ significance level) for the null hypothesis that the difference between modeled and observed TMT trends is due to internal variability alone. Each panel in the right-hand column has a lower (upper) rejection region for large positive (large negative) trends in the model-minus-observed difference series. The lower (upper) rejection region spans the $p$-value range 0 to 0.1 (0.9 to 1.0). The $y$-axis range was extended to -0.06 to facilitate visual display of $p$-values at or close to zero. To calculate the actual values of the $\gamma_{2}$ and $\gamma_{3}$ statistics in Figs. 3D and F, the maximally overlapping $L$-year trends were divided into two sets of approximately equal size ("SET 1" and "SET 2"; see Methods). The dashed vertical lines in the right-hand column panels denote the final month of the last $L$-year trend in SET 1 .

Figure 3: Asymmetries in the statistical significance of differences between modeled and observed tropospheric temperature trends. Results are for maximally overlapping 10-year trends in near-global averages of corrected TMT. We calculate three asymmetry statistics. The first compares the numbers of significant positive and significant negative trends in the $\Delta T_{f-o}(k, t)$ difference time series (panel A). Subtracting the number of significant negative trends from the number of significant positive trends 
yields the $\gamma_{1}$ statistic (panel B). The second statistic gauges asymmetry in the temporal distribution of positive trends in the difference series (panel C). To quantify this asymmetry, we split the number of maximally overlapping 10-year trends into two sets of approximately equal size. Trends sampling earlier (later) portions of the difference series are in SET1 (SET 2). The difference in the number of positive trends (SET1 minus SET2) is the $\gamma_{2}$ statistic (panel D). The third asymmetry statistic relies on the average $p$-values of the individual trends in SET1 and SET2 (panel E). The difference between these set-average $p$-values is $\gamma_{3}$ (panel F). The vertical lines in panels $\mathrm{B}, \mathrm{D}$, and $\mathrm{F}$ are the actual values of $\gamma_{1}, \gamma_{2}$ and $\gamma_{3}$. The grey histograms in panels $\mathrm{B}, \mathrm{D}$, and $\mathrm{F}$ are null distributions of the asymmetry statistics, which were generated using 5,000 realizations of surrogate observations (see Methods).

Figure 4: Overall statistical significance of the $\gamma_{1}, \gamma_{2}$ and $\gamma_{3}$ asymmetry statistics as a function of the analysis timescale and the satellite data used to compute the "MMA minus observed" difference time series. Results are estimates of $p_{\gamma_{1}}, p_{\gamma_{2}}$ and $p_{\gamma_{3}}$, the probabilities that the actual value of the asymmetry statistic could have been obtained by natural internal variability alone (panels $\mathrm{A}, \mathrm{B}$, and $\mathrm{C}$, respectively). The magenta lines in panels $\mathrm{A}, \mathrm{B}$, and $\mathrm{C}$ are the averages (over the three recent observational datasets and the five analysis timescales) of $p_{\gamma_{1}}, p_{\gamma_{2}}$ and $p_{\gamma_{3}}$. Zero values of the probabilities are indicated by colored arrows. The $y$-axis range in panels $\mathrm{A}$ and $\mathrm{B}$ is substantially smaller than in panel C. For further details refer to the caption of Fig. 3 and the Methods section. 
Model and Observed TMT Data and Difference Time Series
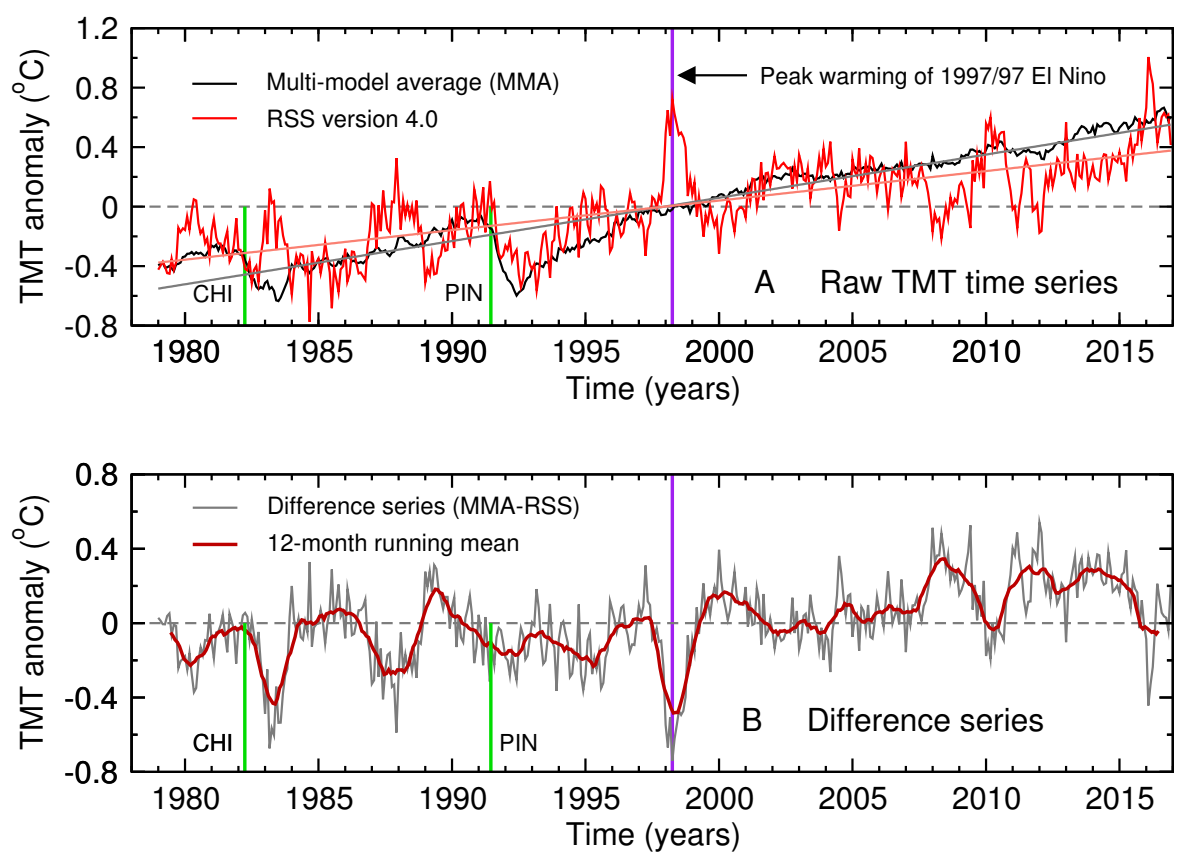

Figure 1: Santer et al. 


\section{TMT: Tests of Near-Global Difference Series Trends Against Internal Climate Variability}

Trends in difference series (MMA-OBS)
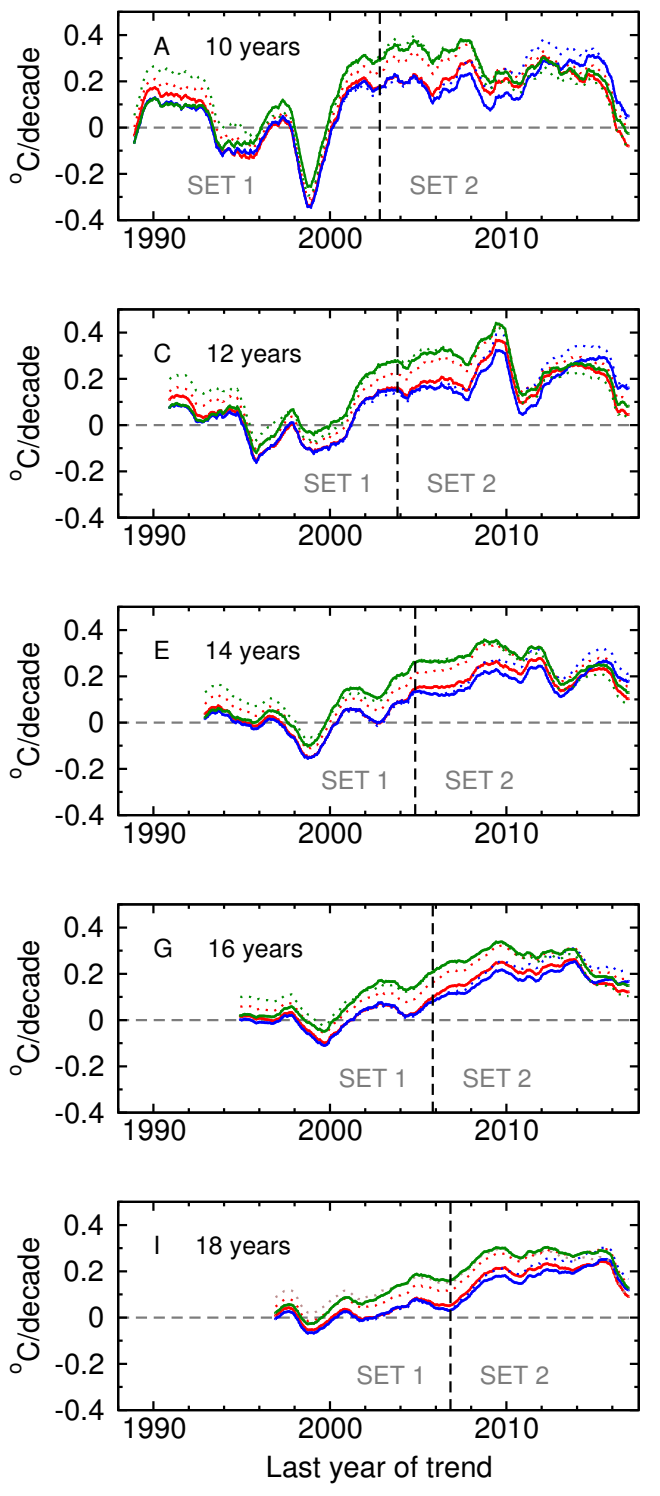

RSS version 3.3 RSS version 4.0

NOAA/STAR version 3.0 NOAA/STAR version 4.0
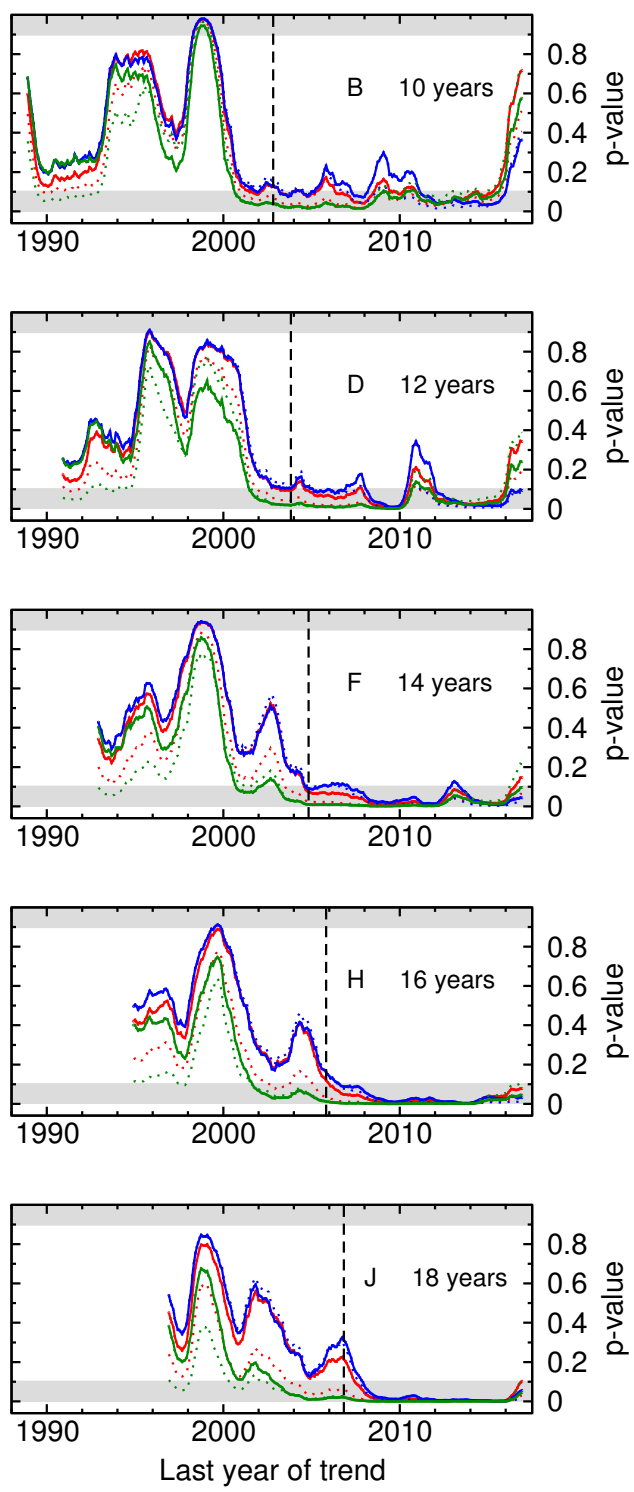

Figure 2: Santer et al. 


\section{Asymmetries in Significance of Model-Minus-OBS TMT Differences (10-yr trends)}

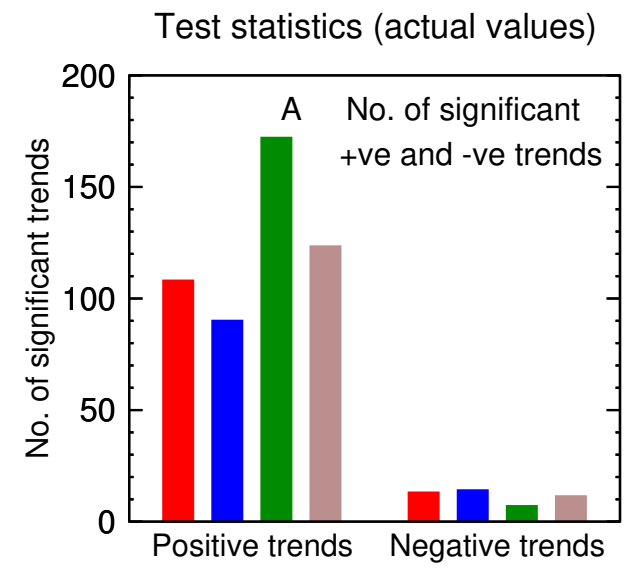

Test statistics (actual, SurrOBS values)
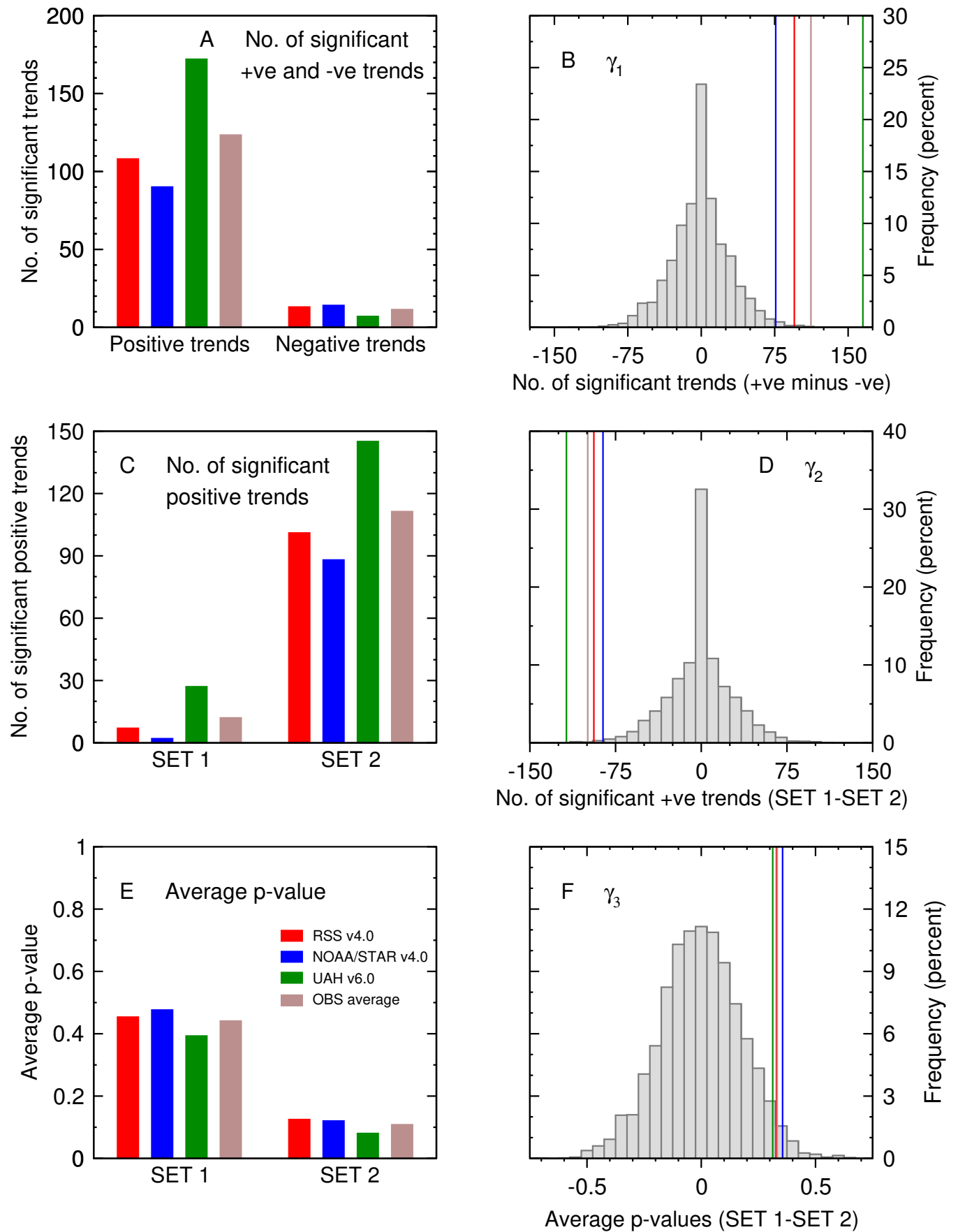

Figure 3: Santer et al. 


\section{Overall Significance of Actual Asymmetry Statistics}

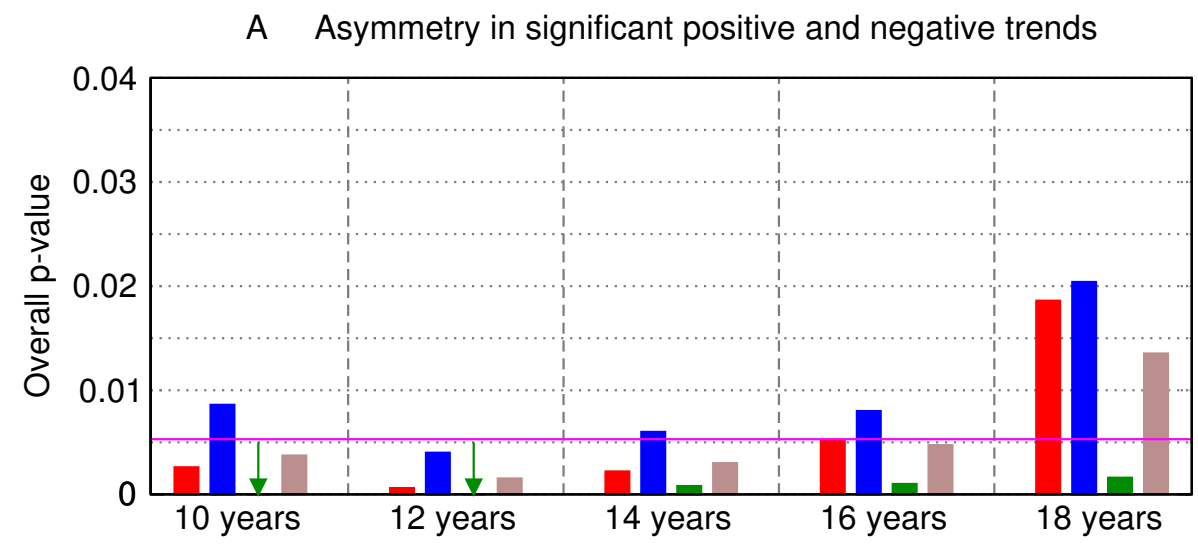

B Asymmetry in significant positive trends (SET 1 minus SET 2)

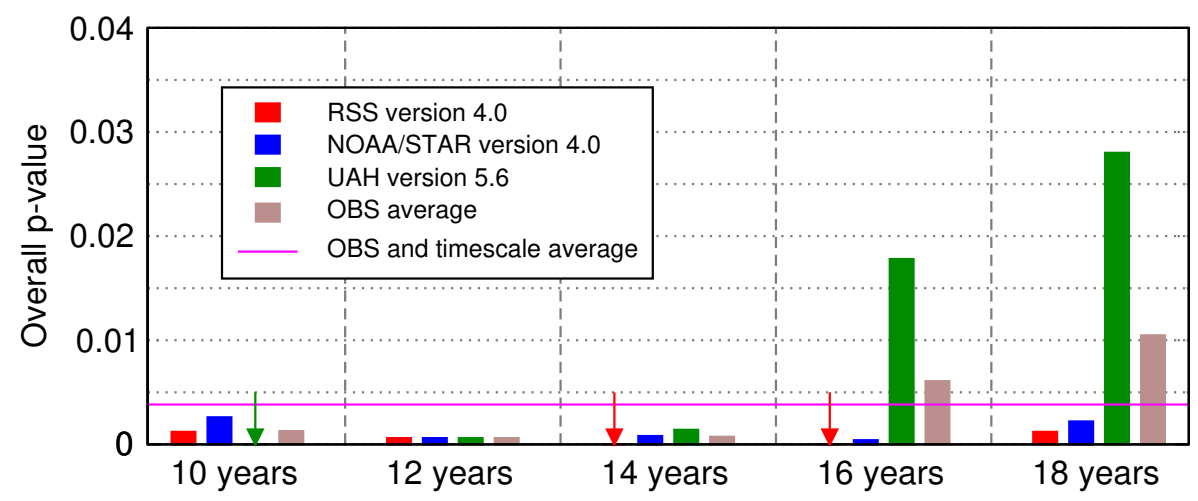

C Asymmetry in average $p$-values (SET 1 minus SET 2)

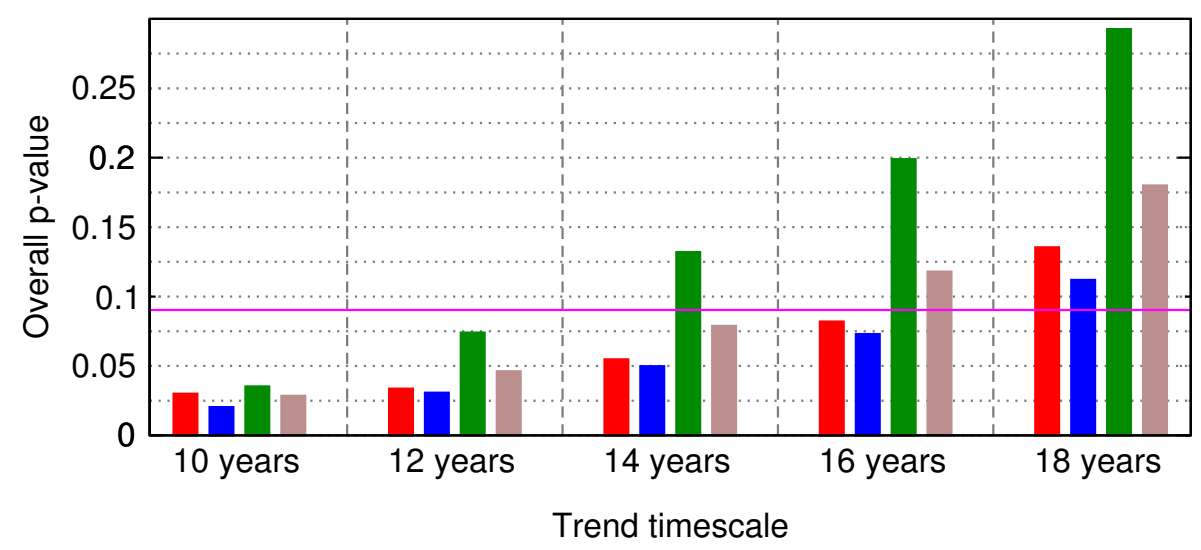

Figure 4: Santer et al. 